\title{
Metodología para la creación de un catálogo de programas de teatro
}

\author{
Cristina Herrero Pascual \\ Facultad de Ciencias de la Documentación, Murcia \\ Jesús Pérez Laserna \\ Biblioteca Regional de Murcia
}

\subsection{Resumen}

Desarrollo de una metodología para el tratamiento documental de una colección de programas de teatro. Esto supone la definición del tipo documental para crear un formato de catalogación que se adapte a sus características especiales. Se han realizado unas normas de descripción para la creación de registros que se puedan incluir en el catálogo general de la Universidad de Murcia pero respetando las características de estos documentos. El objetivo de este trabajo es poner al servicio de los investigadores un volumen importante de información sobre programación teatral nacional e internacional (Autor).

Palabras clave: Programas de teatro. Formato IBERMARC. Análisis documental. Catálogos.

\subsection{Abstract}

Methodology for the cataloguing and indexing of a collection of theatre programmes. It requires the definition of a document type and thereafter the creation of a cataloguing format adapted to its special characteristics. The document description standard for such records to be included in the OPAC of the University of Murcia (Spain) is analysed. The final aim of this work is to offer researchers a great volume of information on national and international theatre programmes.

Keywords: Theatre programmes. IBERMARC format. Cataloguing and Classification. Catalogues.

\section{Introducción}

El fondo documental que ha dado origen a este trabajo está constituido por la colección particular de programas de teatro y documentos afines propiedad del titular de la Cátedra de Teatro de la Universidad de Murcia, Dr. César Oliva. 
La colección consta de alrededor de 2000 documentos recopilados desde los años sesenta que contienen información sobre compañías teatrales, representaciones, teatros, obras, festivales, directores, intérpretes y cualquier personaje o hecho relacionado con el teatro. La mayor parte son programas españoles pero hay también información de otros países.

Este trabajo se encuadra en un proyecto amplio de ordenación, catalogación y digitalización de todo el fondo documental, del cual constituye su primera fase. El resultado será una base de datos multimedia de programas de teatro puesta al servicio de la investigación. Para ello se ha diseñado una metodología basada en el estudio de los documentos, los objetivos que se quieren conseguir y los medios técnicos disponibles.

Este proyecto tiene varios antecedentes en España:

- El catálogo de monografías modernas de la Biblioteca Nacional (1), en el que aparecen programas de teatro que tienen depósito legal. Es un catálogo parcial porque la mayoría de los programas no lo tienen. Además, recoge solo los que tiene forma física de libro, no los folletos, por lo que es muy restringido. En total suponen cuarenta registros de programas desde 1962. Se le ha dado a los documentos tratamiento de monografías, dando preferencia al autor de la obra en el punto de acceso principal y, en segundo lugar, al título de la obra. Se recuperan por materias porque todos tienen dos descriptores comunes: teatro y programas.

- El Museo del Teatro de Almagro (2) posee una colección de programas de teatro, de casi todos los teatros de Madrid, desde 1843 hasta los primeros años del siglo XX: Teatro Real, Príncipe Alfonso, Príncipe, De la Cruz, Teatro del Circo, Alhambra, Apolo, Princesa, Felipe, Del Odeón (actual Calderón), etc., además de los procedentes de otras provincias e importantes donaciones. Desde su creación en 1924 ha recogido los programas de todos los teatros de España. Tiene además colecciones de dibujos en la sección de escenografía, maquetas y un importante archivo musical. Tiene un problema, a saber, la base de datos no puede ser consultada más que en el propio centro, lo cual dificulta enormemente el acceso a la información. Respecto al tratamiento documental, se ha dado preferencia a las compañías como elemento principal de recuperación.

- El Centro de Documentación Teatral (3), en Madrid, dependiente de la Subdirección General de Teatro del Instituto Nacional de las Artes Escénicas y de la Música, funciona desde 1971 con la finalidad de recopilar sistemáticamente, custodiar y poner en condiciones de estudio e investigación todas aquellas aportaciones que están en relación con el hecho teatral, tanto en su soporte escrito como audiovisual e informático. Recoge

Scire. $6: 2$ (jul.-dic. 2000) 59-77. 
documentación nacional y de otros países de teatro y sobre teatro, por lo que es un centro para la investigación teatral. En cuanto a los programas de teatro, su colección parte de 1985, pero no es exhaustiva porque aceptan solo los que les mandan de las compañías. Publica el Anuario Teatral de las Artes Escénicas de España, donde da información de su actividad y hace difusión de sus fondos más interesantes.

Antes de iniciar el trabajo se ha examinado la bibliografía existente sobre "documentación" en relación con el teatro, entendido éste no como fenómeno literario sino como espectáculo. Se trataba de buscar los trabajos realizados que supusieran recopilación y análisis de datos sobre el tema. El resultado de la búsqueda nos ha permitido sacar varias conclusiones que han sido, a su vez, punto de partida de este trabajo.

- Existe un grupo de obras de referencia sobre programación (guías, directorios, etc.) tanto a nivel nacional como por teatros.

- Se han realizado inventarios y catálogos de obras, actores, directores, etc., que suponen una información sometida a análisis documental.

- Aparecen varias publicaciones periódicas que se podrían encuadrar en la Documentación Teatral, aunque la clasificación de estos documentos es relativa.

- Hay solo una publicación que contiene la programación del Centro Dramático Nacional en fechas concretas.

Tradicionalmente la fuente de información sobre programación teatral y teatros en España ha sido la prensa, donde se refleja la actividad local sobre el tema. Esto supone que para recoger la información hay que consultar los periódicos de una época, o ciudad, o región, etc., lo cual es un trabajo importante.

Con este proyecto que vamos a desarrollar se pretende crear un instrumento de descripción con información sobre obras, autores, compañías, actores, directores, teatros y toda la información relacionada que, en una sola fuente, proporcione la información necesaria para la investigación o el conocimiento de la programación teatral.

\section{Metodología}

La metodología utilizada para realizar este proyecto está constituida por cuatro etapas. Se parte de la definición del tipo documental para, una vez establecido éste, crear un formato y unas normas de descripción propias que permitan el almacenamiento y recuperación de la información. La última fase, la de digitalización, se ha planteado, pero no se ha desarrollado en este proyecto. 


\subsection{Tipo documental}

La primera fase metodológica ha sido la definición del tipo documental como punto de partida del trabajo a realizar. La documentación mayoritaria son programas de teatro, aunque hay otros documentos relacionados como programas de homenajes, aniversarios de autores (Centenario de García Lorca), publicidad de compañías y otros. El interés documental de todos es igual pero se ha decidido unificarlos bajo la denominación de programas de teatro porque son mayoría.

Los programas de teatro no son un tipo documental reconocido por los manuales y las normas documentales, por lo que es necesario darle un contenido documental a esta definición. De la observación directa de estos documentos se puede destacar varias características:

- Son documentos textuales ya que una parte importante de ellos está constituida por texto impreso. Incluyen datos de la obra, biografías de autores, historia de las compañías, y, en algunos casos muy interesantes, el texto de la obra original o de la adaptación. Información importante para investigaciones relacionadas con la materia.

- Son documentos gráficos porque, generalmente, en una proporción del $50 \%$, contienen imágenes que puede tener interés almacenar. Normalmente son escenas de la obra, pero también hay ilustraciones creadas para el programa o reproducciones de retratos del autor de la obra.

- Son monografías en el sentido documental que tiene este término como documento unitario y cerrado. Pero no se le puede aplicar el tratamiento documental - ISBD(M) y formato- que se da a éstas porque los programas contienen una información, reflejada en los dos puntos anteriores, que supera este ámbito para incidir en el de otros documentos. En la descripción de estos documentos hay que incluir información relativa a los intérpretes y otros créditos (iluminación, decorados, etc.) que no son necesarios en las monografías y que aparecen en los formatos de películas y vídeos.

- Son documentos publicados, en algún caso llevan depósito legal, pero con una esperanza de vida muy corta. La difusión es directa, es decir, los programas se entregan en mano a los espectadores cuando van al teatro, o se envían poco tiempo antes de que se realice la representación. Esto supone que en muchos casos la fecha se da por supuesta, sobre todo el año y, en algunos casos, también la ciudad porque se considera que al incluir el nombre del teatro todo el mundo sabe donde está. Al constituirse la colección de programas que nos ocupa la "intemporalidad" de muchos de ellos es un problema para su tratamiento documental. 
- Tienen un componente estético muy importante, porque los programas están creados para representaciones concretas, en un teatro o por una compañía y en un lugar. Esto hace que de una misma obra pueda haber programas completamente distintos, no solo de datos formales — director, intérpretes, etc.—, sino en cuanto a las imágenes asociadas.

De lo anteriormente expuesto, podemos establecer que el tipo documental a tratar, denominado programas de teatro, está constituido por documentos textuales y gráficos, con carácter monográfico y de difusión restringida que contienen programas de obras de teatro y cuya información está condicionada temporal y estéticamente a la representación a la que se refieren.

\subsection{Creación del formato de descripción}

El tratamiento de la información está condicionado por la incorporación del catálogo resultante al catálogo general de la biblioteca de la Universidad de Murcia, por lo que en principio se parte de dos supuestos:

- El sistema de gestión bibliotecaria debe ser ABSYS, porque es el que utiliza la biblioteca de la Universidad de Murcia.

- El formato de descripción debe ser IBERMARC, porque es el que admite ABSYS y porque no se concibe hacer un catálogo en otro formato si se quiere garantizar la compatibilidad de los registros que se van a crear con los de los demás fondos de la biblioteca universitaria.

El primer problema surge cuando al iniciar la catalogación el sistema nos pregunta por el tipo de material que vamos a catalogar. Esto es debido a que ABSYS está adaptado, como hemos dicho antes, a la terminología de la norma ISBD y el formato IBERMARC. Así, aparece una pantalla con los siguientes

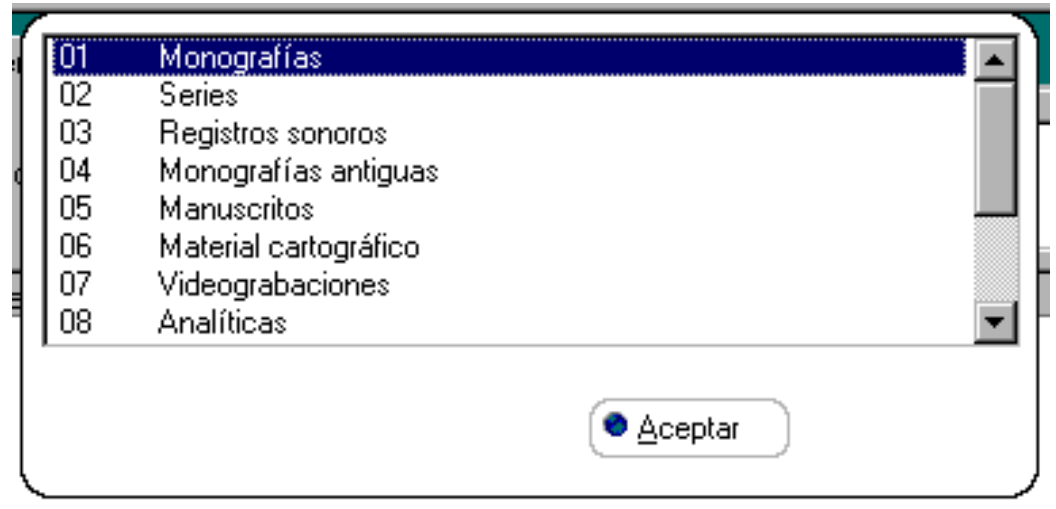

Figura 1. Pantalla de selección del formato de catalogación

Scire. $6: 2$ (jul.-dic. 2000) 59-77. 


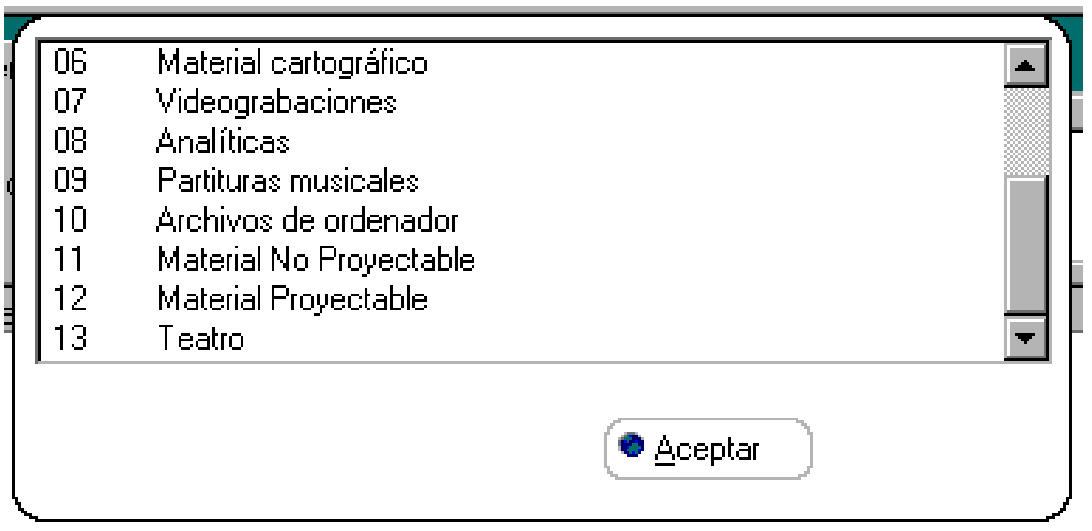

Figura 2. La misma pantalla tras añadir el formato "Teatro”.

tipos documentales, numerados del 1 al 12: monografías, series, registros sonoros, monografías antiguas, manuscritos, material cartográfico, videograbaciones, analíticas, partituras musicales, archivos de ordenador, material no proyectable y material proyectable (Figura 1).

Al definir los programas de teatro como documentos monográficos y gráficos, hemos establecido que para catalogarlos necesitamos el formato de monografías (autor, título, etc.) pero con datos que éste no tiene y que están en el formato de vídeos y películas (director, intérpretes, créditos). Estos datos que constituyen notas bibliográficas en el formato de películas y videograbaciones no se podían integrar en el formato de monografías incluyéndolos en campos de notas de este formato, porque hubiera supuesto una pérdida de consistencia y fiabilidad del catálogo general de la biblioteca, lo cual, además de que no lo habría permitido la sección de proceso técnico, no era en absoluto nuestra intención.

La solución ha sido añadir en ABSYS un formato nuevo para un tipo de material que se ha denominado "teatro", y que constituye el número 13 (Figura 2).

Para ello, partiendo del formato de monografías se han ido copiando en el nuevo los campos de los formatos de otros materiales que iban a ser necesarios, así como quitando del formato original campos que no se iban a utilizar nunca, como el 100, puesto que el punto de acceso principal se iba a dar siempre a la compañía (110), al nombre del festival (111) o, en defecto de ambos, al título (245). La exclusión del campo 100 (punto de acceso principal de autor personal) está basada en que lo que se cataloga no es el texto de la obra de teatro, que justificaría dar preferencia al autor de ésta, sino el programa de la representación en 
la que pensamos que tiene una responsabilidad mayor la compañía. No obstante, el nombre del autor de la obra es también un elemento de recuperación del documento aunque no como entrada principal.

Se ha suprimido el campo 080 y todos los 6 XX puesto que a estos documentos no se les iba a dar ningún tipo de clasificación de materias. Se han incluido campos de notas (5XX) nuevos porque es en este área donde los formatos audiovisuales en general admiten más información específica que no se puede incluir en otras áreas. En concreto, se han introducido los siguientes campos que no tiene el formato de monografías:

- 508: nota de créditos, destinada al director o productor de la obra, puesto que el autor va en el 245 \$c como mención de responsabilidad. Los datos de iluminación, vestuario, decorados, etc., que son muy importantes en teatro no se han recogido en la primera fase del proyecto para abreviar el tiempo.

- 511: intérpretes de la obra.

- 518: para recoger la fecha y lugar de una representación que no se han puesto en el 260. Muy utilizado para las giras de las compañías, ya que en un mismo programa aparece toda la gira por distintas ciudades.

- 550: nombre de una entidad que no es la compañía (110), ni es mención de responsabilidad (245 \$c), ni aparece en el área de publicación (260 \$b).

- 570: nombre de una persona que no aparece como mención de responsabilidad (245 \$c) pero que interesa recoger. Por ejemplo, una participación especial.

Una vez hechas la modificaciones, el formato para el tipo de material " 13 Teatro" del sistema ABSYS de la Universidad de Murcia queda configurado con sus propios campos (Figura 3, en la siguiente página).

Todos los registros tienen dos campos idénticos: el 001, donde aparecen las iniciales del catalogador (jpl); y el 852 de la signatura topográfica, que consta de la palabra Teatro seguida del número de localización.

La experiencia del fondo catalogado hasta el momento es que el formato es suficiente para recoger la información de estos documentos y posteriormente.

\subsection{Redacción de las normas de descripción}

Establecidos los campos del formato IBERMARC que considerábamos necesarios, la siguiente fase era redactar una normativa que, respetando las reglas de catalogación, se adaptara al tipo documental que habíamos definido. Para ello se ha tenido en cuenta la experiencia de los centros especializados en documentación teatral citados en la introducción, relativa sobre todo a dar preferencia a algún punto de acceso y al uso de las notas bibliográficas.

Scire. $6: 2$ (jul.-dic. 2000) 59-77. 


\begin{tabular}{|c|c|}
\hline CAMPOS & CONTENIDO \\
\hline 001 & Control: Iniciales del catalogador: jpl \\
\hline 008 & Códigos de información fija \\
\hline 019 & Depósito Legal \\
\hline 020 & ISBN \\
\hline 033 & Fecha codificada \\
\hline 110 & Punto de acceso principal, nombre de entidad \\
\hline 111 & Punto de acceso principal, nombre de congreso \\
\hline 245 & Título y mención de responsabilidad \\
\hline 250 & Edición \\
\hline 260 & Publicación \\
\hline 300 & Descripción física \\
\hline 490 & Serie \\
\hline 500 & Nota general \\
\hline 505 & Nota de contenido \\
\hline 508 & Nota de créditos \\
\hline 511 & Nota de intérpretes \\
\hline 518 & Nota de lugar y fecha de un acontecimiento \\
\hline 536 & Nota de patrocinador \\
\hline 550 & Nota de entidad \\
\hline 570 & Nota de autor personal \\
\hline 599 & Nota a la ilustración \\
\hline 593 & Nota al encabezamiento \\
\hline 700 & Entrada secundaria de autor personal \\
\hline 710 & Entrada secundaria de entidad \\
\hline 711 & Entrada secundaria nombre de congreso \\
\hline 852 & Signatura topográfica: Teatro...... \\
\hline
\end{tabular}

Figura 3. En sombreado los campos añadidos al formato de monografías.

Las normas de descripción se presentan en el orden de los campos del formato e identificados por el número de etiqueta, puesto que se ha catalogado directamente en el ordenador.

- T001 : Número de control: Todos los registros llevan las iniciales del nombre y apellidos del catalogador, a saber 'jpl'.

- T 008 : Códigos de información: Se han utilizado las posiciones que aparecen en ABSYS para un nivel de catalogación intermedio. 
06 Tipo de fecha:

s Fecha única o probable pero completa del programa, que coincide siempre con la de la representación. Se pone este código cuando en $260 \$ c$ se ha puesto una fecha completa ya sea real, del D.L., aproximada o supuesta.

m Múltiple, cuando hay varias fechas. Es un caso muy frecuente porque hay muchos programas de compañías y teatros que van por temporadas, y éstas empiezan en septiembre de un año y terminan en junio del siguiente. Algunas veces incluso son bianuales. Se utiliza también para programas de festivales de larga duración.

q Fecha incompleta, cuando en 260 \$c aparece [198-]. Muchos programas no tienen fecha alguna y hay que utilizar el dato que más nos aproxime a una data, pero es muy difícil de precisar el año exacto.

07-10 Primera fecha

11-14 Segunda fecha, cuando en 06 se ha puesto 'm'.

15-17 País de publicación, según los códigos normalizados.

18 Ilustraciones: La mayoría de los programas tiene ilustraciones y por tanto en esta posición se pone 'a'.

28 Publicación oficial. Muchos programas son publicaciones oficiales porque hay muy pocas compañías y teatros privados y, cuando lo son, están concertados con el Ministerio de Cultura, por lo que casi todos los registros llevan en esta posición 'o'.

35-37 Lengua de la publicación o primera lengua si hay más, según los códigos normalizados.

- T019: Depósito Legal. Algunos programas tienen esta información, que es importante porque puede ser la única información sobre la fecha y el lugar.

019b/ b/ \$a M-15.659/69

- T 033 : Fecha codificada de la primera representación o representación única en el siguiente orden: año (4 dígitos), mes (2 dígitos) y día (2 dígitos). Por ejemplo:

033b/ b/ \$a 19720429 corresponde a una obra representada el día 29 de abril de 1972.

Si una obra se representa en diferentes fechas y teatros, esta información se pone en T 518: fecha y lugar de un acontecimiento : Teatro Romea (Murcia), 23 enero. Pero si se representa en el mismo teatro varios días, se pone en 033 el primer día y no se consignan los demás. Si faltan cifras por- 
que el programa se refiere solamente a meses o años, en los dígitos que no hay información se ponen ceros. Por ejemplo:

033b/ b/ \$a 19810100 la obra está programada para enero de 1981

- T 110 : Punto de acceso principal por nombre de entidad. Constituye la mayor parte de los puntos de acceso de los programas de teatro. Se ha dado preferencia a la compañía teatral a la hora de escoger el punto de acceso principal sobre el autor de la obra original por las razones expuestas anteriormente. De esta manera la mayoría de los registros llevan un 110 como punto de acceso principal, salvo los festivales que van en un 111. Por ejemplo:

11020 \$a Escuela Superior de Arte Dramático y Danza de Murcia

11020\$a Compañía de Julia Gutiérrez Caba

11020\$a Dagoll-Dagom

Si el nombre de la compañía empieza por artículo, se pospone (5), por ejemplo:

$11020 \$$ a Fura dels Baus, La

Si el nombre de la compañía es el de una persona, se pondrá en orden directo y se especificará que es una compañía, por ejemplo:

11020\$a Emilio Gutiérrez Caba (Compañía)

Si en el programa no aparece el nombre de la compañía, el punto de acceso principal pasará a ser el título de la obra. En estos casos es frecuente que el programa ofrezca el nombre del productor de la obra, pero éste no se utilizará nunca como punto de acceso, sino que se pondrá en 508.

- $T 111$ : Punto de acceso principal por nombre de congreso u otra entidad de carácter temporal: Se utiliza para congresos, festivales, etc., que tienen un nombre oficial y que pueden tener un número de orden porque se celebren periódicamente. Por ejemplo:

1112b/ \$a Festival Internacional de Teatro Maer Menor \$n 19º \$d 1988 \$c San Javier

1112b/ \$a Jornadas Homenaje a José Martín Recuerda \$d 1999 \$c Salobreña

En estos casos los nombres de las compañías y las obras que se representan en el marco del acontecimiento va en el campo 505 como nota de contenido y se les hace entrada secundaria de autor-título y entrada secundaria por la compañía.

- T 245 : Título y mención de responsabilidad: Se registra en este campo el título de la obra y el autor original. Cuando es una adaptación de una obra original, se pone aquí el nombre del adaptador y se añade el de la obra ori- 
ginal si en el programa viene como subtítulo o como mención de responsabilidad, lo que sucede en la mayoría de los casos. Se hace una entrada secundaria por cada uno de los nombres que aparezcan aquí registrados. Por ejemplo:

11020 \$a Centro Dramático Nacional

24513\$a El jardín de los cerezos \$c Antón P. Chejov

70011 \$a Chejov, Anton Pavlovich

$11020 \$ a$ Teatro Estable Castellano

24510 \$a Así que pasen cinco años \$c Federico García Lorca

$70021 \$ a$ García Lorca, Federico

24500 \$a Equus \$c de Peter Shaffer; adaptación, Vicente Balart

70011 \$a Shaffer, Peter

70011 \$a Balart, Vicente \$e adapt.

$24503 \$$ a La mujer de negro \$c adaptada por Stephen Mallatratt a partir de la novela de Susan Hill

70011 \$a Hill, Susan

70011 \$a Mallatratt, Stephen \$e adapt.

$11020 \$ a$ Compañía María José Goyanes

24510\$a Casandra \$c Benito Pérez Galdós ; versión, Francisco Nieva

70021 \$a Pérez Galdós, Benito

70011 \$a Nieva, Francisco \$e adapt.

No se pone en este campo el nombre del director de la obra - aunque en muchos programas consta como mención de responsabilidad, porque va en un campo 508-, ni los patrocinadores que van a un campo 536. No se incluyen en este catálogo los intérpretes de las obras, campo 511, porque se ha dejado para una segunda fase, debido a que su número haría muy lento el control de autoridades. Las entidades que aparezcan en el programa que no sean patrocinadoras, por ejemplo, Red de Teatros \& Auditorios de la Región de Murcia, van en un campo 550 para hacerles después entrada secundaria.

Cuando no sean programas de teatro se incluirá como subtítulo y entre corchetes la denominación que corresponda: Curso, Publicidad o Felicitación navideña, por ejemplo

$11020 \$ a$ Centro Internacional Universitario de Estudios Teatrales y de las Artes Escénicas (Tenerife) 
24510 a Experto Universitario en Teatro y Artes Escénicas \$b : [Curso]

- T 250 : Área de edición: No se ha utilizado este campo hasta el momento porque los programas de teatro no tienen mención de edición. Está reservado a la aparición de ediciones distintas de una gira de una compañía teatral o a programas que presenten versiones distintas de una misma obra en dos idiomas.

- T260 : Datos de publicación: Se utiliza para indicar el lugar, teatro y fecha de la representación que aparece en el programa, ya que normalmente coincide con los datos de publicación. Si una obra se representa en varios sitios, en este campo van los datos de la primera representación que coincide con la fecha que se pone en 008 y en 033 codificada. Las otras representaciones se registran en el campo 518. Se hace siempre una entrada secundaria (710) por el teatro que aparece consignado en este campo, por ejemplo:

2600b/ \$a Murcia \$b Teatro Romea \$c 1984

$71021 \$ a$ Teatro Romea (Murcia)

2600b/ \$a Bilbao \$b Teatro Consulado \$c 1987

$71021 \$ a$ Teatro Consulado (Bilbao)

2600b/ \$a Madrid \$b Sala Olimpia \$c 1984-1985

$71021 \$ a$ Sala Olimpia (Madrid)

Este último programa tiene dos fechas porque contiene la programación de un teatro para una temporada.

Algunas veces el programa no especifica el o los teatros donde se va a representar la obra porque son muy numerosos y se pretende que el mismo programa se entregue en todas las funciones. Suelen tener fecha del depósito legal y los otros datos se registran de la siguiente manera:

2600b/ \$a [España : s.n.], D.L. 1967

- T 300 : Descripción física de los programas, que consta de extensión, otras características físicas y dimensiones. No se incluye el elemento material anejo porque parece que no va a ser necesario. En el subcampo \$a se registra la extensión según las siguientes denominaciones: páginas, hojas, volumen si consta de página u hojas sin numerar, díptico, tríptico o políptico (más de tres pliegues).

El subcampo \$b se utiliza en la mayoría de los casos puesto que casi todos los programas tienen ilustraciones, generalmente fotografías, de la obra o compañía. Si hay que hacer algún comentario a la ilustración se utiliza el 
campo 599. En el subcampo \$c se ponen las dimensiones expresadas como si fuera un libro. Por ejemplo:

300b/ b/ \$a 1 díptico \$b il. \$c 29 cm

$300 \mathrm{~b} / \mathrm{b} / \$ \mathrm{a} 1 \mathrm{v} . \$ \mathrm{~b}$ fot. \$c $29 \mathrm{~cm}$

300b/ b/ \$a 1 tríptico \$b il. \$c 23 cm

599b/ b/ \$a La ilustración es de Javier Mariscal

70011 \$a Mariscal, Javier \$e il.

300b/ b/ \$a 1 políptico \$b il. \$c 26 cm

$599 \mathrm{~b} / \mathrm{b} /$ \$ Reproduce un grabado con retrato de Shakespeare

- T 490 : Serie: Los programas de teatro no aparecen publicados dentro de una serie, pero sí contienen informaciones que se pueden incluir en este campo puesto que supone una publicación de carácter continuo en el marco de un acontecimiento más amplio. Es el caso de los programas de obras incluidas en las campañas nacionales de teatro. La inclusión de esta información en el área de serie permite recuperar y por tanto conocer las campañas que se hicieron ordenadas por años, y las obras que se programaron en ellas. Por ejemplo:

11020\$a Compañía Lope de Vega

24513\$a La vida es sueño \$c de Don Pedro Calderón de la Barca

490 \$a Primera Campaña Nacional de Teatro

$11020 \$ a$ Compañía Titular

24514 \$a Una guerra en cada esquina \$c de Luis Matilla

490 \$a Cicle de teatro contemporani

- T 500 : Nota general: Se incluye información que se considera de interés y que no se pone en otro campo $5 \mathrm{XX}$.

$500 \mathrm{~b} / \mathrm{b} / \$ a$ Incluye texto completo (o parcial) de la obra

$500 \mathrm{~b} / \mathrm{b} / \$ a$ Incluye críticas

500b/ b/ \$a Premio Castilla-La Mancha de Teatro 1998

$500 \mathrm{~b} / \mathrm{b} /$ \$a Obra programada en el marco del seminario sobre "El concierto de San Ovidio y el teatro de Buero Vallejo, Madrid, 1986"

- T 505 : Nota de contenido: Para programas que bajo un título colectivo que puede ser la gira de una compañía, la programación temporal de un teatro, un festival, etc., incluyen varias representaciones. Se describirán en este campo y se hará entradas secundarias por la compañía (si no aparece en 
110), el teatro (si no aparece en 260) y por los autores de las obras. En el caso de los autores serán de autor título. Por ejemplo:

24510\$a Jornadas homenaje a José Martín Recuerda \$c [organizadas por el] Ayuntamiento de Salobreña

5050b/ \$a Contiene: Como las secas cañas del camino ; La llanura ; El teatrito de Don Ramón ; El caraqueño ; Las salvajes en Puente San Gil 70021\$a Martín Recuerda, José \$t Como las secas cañas del camino

70021 \$a Martín Recuerda, José \$t La llanura

70021\$a Martín Recuerda, José \$t El teatrito de Don Ramón

70021 \$a Martín Recuerda, José \$t El caraqueño

70021\$a Martín Recuerda, José \$t Las salvajes en Puente San Gil

- T 508 : Nota de créditos: Se ha destinado a recoger el nombre del director y/o el productor de la obra. Se han hecho entradas secundarias de los nombres de todos ellos.

508b/ b/ \$a Dirección: César Oliva

70011 \$a Oliva, César \$e dir.

508b/ b/ \$a Producción: Amparo Soler Leal

$70021 \$ a$ Soler Leal, Amparo

Las Reglas de catalogación no contemplan la abreviatura de productor/producción.

- T 511 : Nota de intérpretes: La inclusión de los intérpretes de las obras en los registros se ha dejado para una segunda fase porque, como se ha expuesto anteriormente, el control de autoridades aplicado a todos los nombres que podían aparecer hubiera hecho muy largo el trabajo.

- T 518: Nota de fecha y lugar de un acontecimiento: Se ha utilizado para repetir el campo 260 en los casos en los que una obra se representa en varios teatros, lo que conlleva lugares y fechas distintas. Se hacen entradas secundarias (710) por todos los teatros que aparezcan en este campo. Por ejemplo:

033 \$a 19980100 fecha codificada de la primera representación.

2600b/ \$a Murcia \$b Teatro Romea \$c 1998

518b/ b/ \$aTeatro Guerra (Lorca), 5 de enero ; Teatro Vico (Jumilla), 10 de enero.

$71021 \$ a$ Teatro Guerra (Lorca)

$71021 \$ a$ Teatro Vico (Jumilla) 
- T 536 : Nota de patrocinador: Se hará constar cuando una obra esté patrocinada por una institución, así conste en el documento e interese recuperar información por su nombre. Cuando se incluya, se hará entrada secundaria (normalmente 710) por el nombre del mismo. Por ejemplo:

$5360 \mathrm{~b} / \mathrm{b} /$ \$a Patrocinado por The British Council

$71021 \$ a$ British Council London

No se han considerado patrocinadores los organismos de la administración central, autonómica o local que aparecen avalando o subvencionado una representación porque, aunque existen muchas compañías y algunos teatros privados, todos están subvencionados o tienen concierto con las instituciones. Esto supone que en la inmensa mayoría de los registros aparecería el Ministerio de Cultura, el INAEM, y otros organismos, lo que restaría interés a su recuperación.

- T550: Nota de entidad responsable: Dedicada al nombre de una entidad que no es la compañía, ni el patrocinador, pero que es interesante recogerlo para su posterior recuperación. Así, por ejemplo, los programas de los teatros de la región de Murcia llevan todos la referencia a la Red de Teatros \& Auditorios de la Región de Murcia. Esta información no puede aparecer en el 260 porque no es un teatro donde se representa una obra y, por lo tanto, tampoco en 518, pero su recuperación es interesante. La inclusión en este campo permite hacerle una entrada secundaria (campo 710). Por ejemplo:

2600b/ \$a Murcia \$b Teatro Romea \$c 1998

550b/ b/ \$a Red de Teatros \& Auditorios de la Región de Murcia

$71021 \$$ a Red de Teatros \& Auditorios de la Región de Murcia

- T 570 : Nota de responsable personal: Destinada al nombre de una persona que no es autor ni director de la obra pero que se quiere incluir en la descripción porque tiene una participación especial o es una personalidad relevante. Por ejemplo, un programa de la obra Bodas de Sangre, de Federico García Lorca, que incluye un comentario de Pablo Neruda:

$570 \mathrm{~b} / \mathrm{b} / \$$ a Texto de Pablo Neruda el programa reproduce un texto de este autor que se ha considerado oportuno relacionarlo con la obra programada.

$70011 \$$ a Neruda, Pablo

- T 593 : Nota al encabezamiento: para una compañía o festival que cambia de nombre, o tiene varias subcompañías.

- T 599 : Nota sobre ilustraciones: Se utilizarán cuando vayan firmadas, sean una reproducción de una obra conocida, etc. Por ejemplo: 
300b/ b/ \$a 1 tríptico \$b il. \$c 23 cm

599b/ b/ \$a La ilustración es de Javier Mariscal

70011 \$a Mariscal, Javier \$e il.

- T 852 : Signatura topográfica: Se compone del término "Teatro" seguido del número de la caja y, a continuación, el número de orden dentro de ésta.

852 \$a Teatro 2-14

- T 700 : Entradas secundarias de autor personal: Como ya se ha expuesto, se han hecho a los autores de las obras, directores y otros nombres de persona que aparezcan en la descripción y se quieran recuperar.

- 7710 : Entradas secundarias de entidad: Se harán a todos los teatros, compañías (cuando no se deban codificar en el campo 110), patrocinadores y entidades que aparezcan en el campo 550.

En todos los campos 1XX y 7XX utilizados se ha aplicado un estricto control de autoridades, lo que ha supuesto crear un número amplio de autoridades que no estaban en la base de datos de la Universidad de Murcia, dadas las características especiales de los documentos objeto de descripción.

Se han normalizado los nombres de los teatros, compañías, patrocinadores, autores, artistas, etc., lo que ha hecho especialmente lenta la catalogación de las obras.

\subsection{Almacenamiento y digitalización}

Los registros creados según las normas y el formato descritos están integrados en el catálogo general de la Biblioteca de la Universidad de Murcia (5) puesto que, como se ha dicho al principio, la Cátedra de Teatro consideraba que son fondos bibliográficos al servicio de la investigación. Pero, esta circunstancia, que por un lado es positiva puesto que permite hacer accesible esta información a toda la comunidad universitaria, condiciona el tratamiento que se ha de dar a las imágenes.

El objetivo del proyecto es la creación del catálogo en una primera fase y la digitalización de los programas en una posterior para poder recuperar las imágenes y los textos a través de la información del catálogo.

Uno de los problemas que tiene el formato MARC en general es la imposibilidad de almacenar imágenes y sonido, a pesar de que en los centros de información conviven actualmente todo tipo de soportes y se camina hacia una generalización de los multimedia como soportes y medios de información. De hecho, las imágenes digitales son hoy accesibles para cualquier usuario en la mayoría de los equipos y programas con los que se trabaja actualmente. Las imágenes han pasado a ocupar un espacio predominante en la interacción del hombre con el orde- 
nador, ya que muchos servidores WEB permiten que los usuarios visualicen diariamente millones de imágenes electrónicas.

Hacemos estas consideraciones porque, al estar el proyecto desarrollando actualmente la fase de catalogación, no se ha determinado el sistema de procesamiento de imágenes que se va a adoptar, pero sí se pueden hacer algunas consideraciones sobre las necesidades y prestaciones que el sistema debe resolver.

Los programas de teatro pueden, según la clasificación de Hernández Pérez (1999, p. 207), considerarse documentos impresos cuyo contenido más importante es el texto, aunque contengan gráficos. Son imágenes generadas por medio distinto al ordenador que, capturadas luego a través de scanner o cámara digital, pueden ser tratadas por computadora. Esta es la situación exacta de los programas de teatro, que son documentos ya constituidos de forma impresa con texto e imágenes para cuyo tratamiento, almacenamiento y posterior recuperación se va a utilizar el ordenador.

Para ello es necesario un sistema de gestión con una gran capacidad de almacenamiento puesto que las imágenes digitales ocupan mucho espacio en la memoria. El espacio de un folio con una imagen ocupa en un ordenador diez veces más espacio que el mismo con texto. Por eso se han desarrollado los sistemas de compresión, que permiten reducir el tamaño final de un fichero hasta un noventa por cien. (Hernández, 1999, p. 221).

La digitalización se puede hacer por medio de escáner o por medio de una cámara digital. Una vez captada la imagen digital se almacena en una memoria mediante los llamados programas procesadores de imágenes de los que actualmente existen muchos disponibles en el mercado. Las compañías más importantes son Micrografx, Corel y Adobe, aunque existen otros muchos, como Paint Shop Pro. Todos estos programas están destinados a procesar imágenes ya captadas que es el tema que nos ocupa. Permiten recortar imágenes cuando se considere necesario.

Finalmente las imágenes se almacenan en el disco duro para conseguir una recuperación a largo plazo, aunque se puede utilizar también discos CD-Rom o videodiscos, y beneficiarse de los sistemas de compresión (Winzip u otro).

El resultado es un banco de imágenes multimedia que ofrece los programas sin tener que acceder directamente al documento original. Esto permite el acceso remoto y la posibilidad de hacer copias, prestaciones imprescindibles de cara a la investigación, la comparación, la utilización como ilustraciones en textos, etc. 


\section{Conclusiones}

Como se han expuesto los resultados del proyecto de manera parcial, es decir, según las distintas etapas metodológicas, vamos a centrarnos en el resultado final y las conclusiones que se extraen de ello.

El catálogo multimedia de programas de teatro va a permitir acceder a la información de manera exhaustiva. Partiendo del modelo de registro (Figura 4) la información que proporciona se puede sintetizar en los siguientes puntos:

- Programación de cada teatro, recuperando las formas normalizadas del nombre por el campo 710.

- Programación de cada compañía, por medio de las formas normalizadas incluídas en los campos 110 y 710.

- Teatros donde actúa una compañía en gira, combinando los nombres de los teatros con los de las compañías.

- Programación de festivales y homenajes, a través de la información del campo 111 y 711 .

- Representaciones de una determinada obra, buscando por título y teatros.

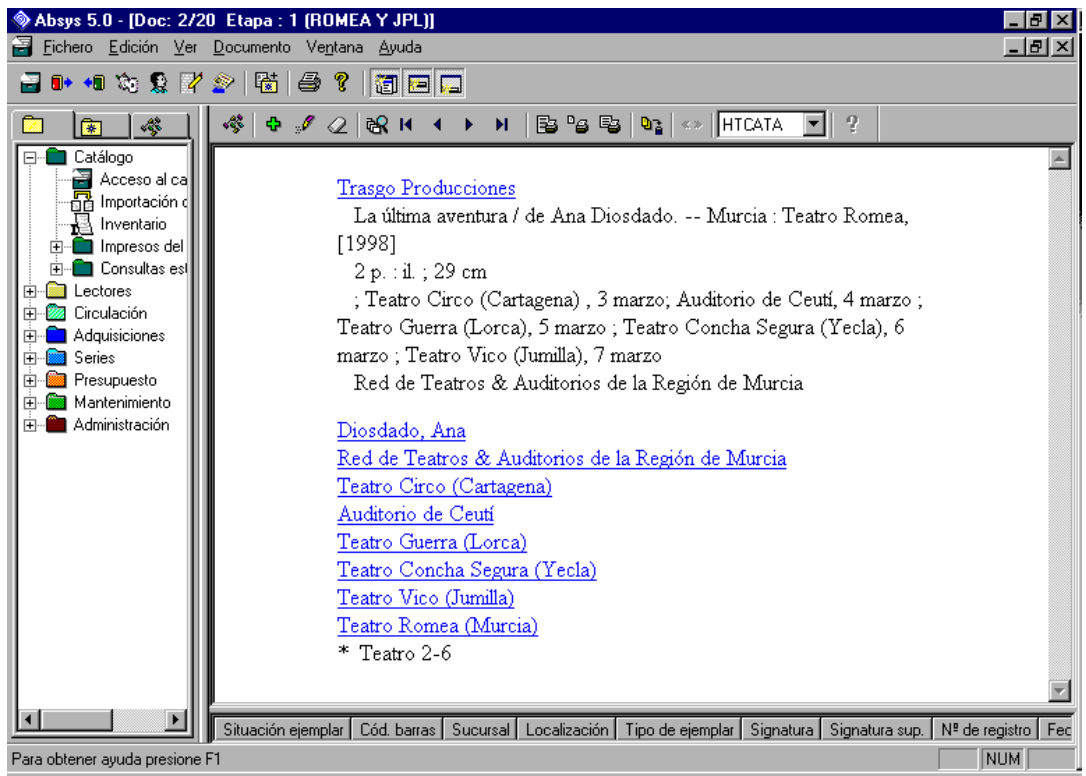

Figura 4. Modelo de registro

Scire. $6: 2$ (jul.-dic. 2000) 59-77. 
- Conocer qué obras son más representadas en una época determinada, combinando búsqueda por título y por fecha de representación.

- Autores más representados, comparando la información del campo 110 con el total de registros.

- Directores y productores de las representaciones, recuperando igualmente la información del campo 110.

-Participaciones especiales en las representaciones: dibujos, comentarios, críticas, premios recibidos; todo ello a partir de la información recogida en los campos de notas $(5 \mathrm{XX})$ que ha dado lugar a entradas secundarias de nombres de persona o premios.

La imposibilidad de integrar actualmente el catálogo IBERMARC con las imágenes esperamos que sea un problema de próxima solución.

\section{Notas}

(1) URL: 〈http://www.bne.es>., fecha de consulta: 30-10-2000.

(2) Se accede a través de la página web del Ministerio de Cultura: URL: <http://www.mcu.es〉.

(3) Se accede igualmente a través de la página web del Ministerio de Cultura.

(4) El campo 110 no tiene un indicador para evitar la alfabetización de los artículos y hemos creído conveniente evitarlos.

(5) URL: 〈http://www.umu.es〉.

\section{Bibliografía}

ABSYS: Sistema Integrado de Gestión Bibliotecaria: Manual de usuario: versión 5.0.

[S.1.] : Servicios de Teledocumentación, 1998.

Biblioteca Nacional (España). Autoridades de la Biblioteca Nacional [Documento electrónico]. Madrid : Biblioteca Nacional, 1997-.

CD Marc Names [Documento electrónico]. Washington : Library of Congress, 1995-.

Consejo Superior de Investigaciones Científicas. Lista de entidades en la base de datos

CIRBIC. Madrid : CSIC, Programa de Informatización de Bibliotecas, 1989.

Díaz Carrera, C. (dir.). Los materiales especiales en las bibliotecas. Gijón : Trea, 1998.

Formato IBERMARC para registros de autoridad. Madrid : Biblioteca Nacional, 1999.

Formato IBERMARC par registros bibliográficos. Madrid : Biblioteca Nacional, 1995.

Hernández Pérez, A. La fotografía digital. // Valle Gastaminza, F. del. Manual de Documentación fotográfica. Madrid : Síntesis, 1999, p. 207.

IFLA-FIAB. Unimarc-Authorities : Universal Format for Authorities. München : Saur, 1991.

Reglas de catalogación. Ed. nuevamente revisada. Madrid : Ministerio de Educación y Cultura, 1999.

Scire. 6 : 2 (jul.-dic. 2000) 59-77. 